\title{
Entrevista não-diretiva: uma possibilidade de abordagem em grupo
}

Non-directive interview: a possibility of group approach

Entrevista no directiva: una posibilidad de abordaje en grupo

\section{Maria Vitória Hoffmann', Isabel Cristina Santos Oliveira'}

'Universidade Federal do Rio de Janeiro. Escola de Enfermagem Anna Nery. Rio de Janeiro, SP

Submissão: 12/08/2008

Aprovação: 19/10/2009

\section{RESUMO}

Relato de experiência Que descreve a abordagem metodológica entrevista não-diretiva, explicitando a possibilidade da abordagem em grupo. Apresenta os estudos que utilizaram este tipo de entrevista em grupo e a dinâmica de coleta de dados. Conclui-se que a abordagem possibilita ao pesquisador articular teoria e prática em torno de uma proposta de estudo.

Descritores: Pesquisa Qualitativa; Coleta de dados; Entrevista; Família.

\begin{abstract}
Experience report that describes the methodological approach - non-directive interview, highlighting the possibility of group approach. It presents the studies that used this type of group and the dynamics of data collection. It was concluded that the approach enables the researcher to combine theory and practice around a study proposition.

Descriptores: Qualitative research; Data collection; Interview; Family.
\end{abstract}

\section{RESUMEN}

Relato de experiencia Que describe el abordaje metodológico - entrevista no directiva; explicita la posibilidad del abordaje en grupo. Presenta los estudios que utilizaron la entrevista no directiva en grupo y la dinámica de la recollección de datos. Se concluye que el abordaje posibilita al investigador articular teoría y práctica en torno de una propuesta de estudio.

Descriptores: Investigación cualitativa; Recollección de datos; Entrevista; Familia. 


\section{INTRODUÇÃO}

Esse estudo teve sua origem em uma das atividades do Grupo de Pesquisa "Saúde da Criança/ Cenário Hospitalar", cuja autora relata a experiência de utilizar a entrevista não-diretiva em grupo como uma forma de abordagem dos familiares.

Vale ressaltar Que, nessa atividade, os membros do referido grupo têm a oportunidade de discutir o desenvolvimento de seus projetos, apontar suas potencialidades e suas limitações para buscar o fortalecimento do grupo de pesquisa, permitindo diferentes olhares acerca da natureza do fenômeno.

Dessa forma, o aluno frente ao desafio de descrever a realidade empírica e articular com a teoria, apresenta dificuldades devido a falta de conhecimentos teórico-metodológicos, angústia, ansiedade e medo, Que se tornam bloqueios na elaboração do texto. O problema aumenta Quando o aluno está diante de uma série de Questões, Que incluem algumas escolhas ${ }^{(1)}$.

Com isso torna-se importante conhecer as diferentes opções. No referencial filosófico e/ou teórico escolhido para a pesQuisa, há um método (positivista, materialista dialético, fenomenológico, entre outros) correspondente e diversas técnicas de coleta de dados (pesquisa-participante, entrevista, Questionário e outras) e de análise de dados (epidemiológico-estatístico, análise do discurso, e outras) para atingir resultados diferentes para uma mesma Questão( ${ }^{(1)}$.

Nesse sentido, é recomendado que a escolha do tema seja do interesse do pesquisador (em nível de leitura, atitude política, cultural ou religiosa), as suas fontes de consulta estejam ao alcance de suas experiências. Acima de tudo, para desenvolver uma pesquisa, o pesquisador tem Que apresentar disponibilidade, aderência ao objeto estudado, ter um comprometimento e não apenas se tornar uma exigência de algum curso de graduação como trabalho de conclusão de curso ou ainda tende a consolidar-se no lato sensu (pósgraduação) e stricto sensu (mestrado e doutorado) ${ }^{(2)}$.

A escolha é fruto da inserção do pesquisador na sociedade com um olhar sobre o objeto de estudo para posteriormente optar pela abordagem metodológica mais adequada para que os objetivos possam ser alcançados ${ }^{(3)}$

Durante a elaboração da minha dissertação de mestrado, procurei seguir as etapas mencionadas e elegi o tema do meu interesse, com o Qual tenho grande afinidade no meu cotidiano como enfermeira/docente inserida num projeto de extensão universitária "Saúde na Foz do Rio Doce". Com objeto selecionado, emergiu os objetivos para entender o mundo dos sujeitos, fornecerem uma descrição sobre o uso da pesQuisa Qualitativa com entrevista não diretiva e oferecer subsídios para pesQuisas futuras.

\section{PESQUISA QUALITATIVA E ENTREVISTA NÃO-DIRETIVA.}

A entrevista não-diretiva é originária de uma técnica psicoterapêutica, centrada no cliente e desenvolvida por Carl Rogers utilizada para obter informações baseadas no discurso livre do entrevistado; e pressupõe que o informante é competente para exprimir com clareza sua experiência, é uma maneira de receber informações do entrevistado da maneira Que ele desejar, manifestar em seus atos o significado Que têm no contexto em Que eles se realizam,podendo revelar tanto a singularidade Quanto a historicidade dos atos, concepções e idéias $^{(4)}$.
O entrevistador mantém-se atento e receptivo a todas as informações significativas independentemente às Questões Que só interessem a pesquisa; intervém com discreta interrogação de conteúdo ou sugestões Que estimulem a comunicação verbal e atitudinais sem Qualificar os atos do informante, exortá-lo, aconselhálo ou discordar das suas interpretações, sem um preparo prévio; bem como na comunicação não verbal dos sujeitos ${ }^{(4)}$.

A entrevista não-diretiva possui vantagens e limites Que devem ser ponderados pelo pesQuisador como: profusão de dados Que devem ser reduzidos; interferências emocionais e a tendência do entrevistado se posicionar frente a todas as situações relatadas. A vantagem do contato imediato com Questões relevantes pode aprofundar a significação dos fenômenos Que está sendo estudado ${ }^{(4)}$.

O entrevistador não formula perguntas, apenas sugere o tema geral em estudo, levando o entrevistado a um processo de reflexão sobre o tema; não dirige o entrevistado apenas guia; desenvolve e aprofunda os pontos Que coloca espontaneamente; facilita o processo de entrevista, retornando o tema na possibilidade de esclarecer ou aprofundar as idéias do entrevistado; evita atitudes autoritárias ou paternalistas; manifesta cooperação e esclarece dúvidas ${ }^{(4)}$.É uma técnica "muito poderosa", particularmente, para detectar atitudes, motivações e opiniões dos entrevistados ${ }^{(5)}$.

A seleção do sujeito inicia-se com a descrição e delimitação da população dos sujeitos a serem entrevistados, assim como o seu grau de representatividade no grupo social em estudo, constituindo um problema a ser imediatamente enfrentado. Isto pressupõe uma imersão do pesQuisador na vida, no contexto e nas informações das pessoas ou grupos envolvidos na pesQuisa ${ }^{(4)}$.

À medida Que se colhe o depoimento, vão sendo levantadas $\mathrm{e}$ organizadas as informações relativas ao objeto da investigação e, dependendo do volume e Qualidade delas, o material de análise torna-se cada vez mais consistente e denso. Quando já é possível identificar padrões simbólicos, práticas, sistema classificatório, categorias de análise da realidade e visões de mundo do universo em Questão, e as recorrências atingem o Que se convencional chamar de ponto de "saturação", dá-se por finalizado o trabalho de campo, sabendo que se pode (e deve) voltar para esclarecimentos ${ }^{(4)}$.

As situações nas Quais se verificam os contatos entre pesquisador e sujeitos da pesquisa configuram-se como parte integrante do material de análise. São eles: o registro do modo como são estabelecidos os contatos; a forma de o entrevistador ser recebido pelo entrevistado; o grau de disponibilidade; o local; a postura adotada durante a coleta do depoimento; gestos; sinais corporais e/ou mudanças de tom de voz; entre outros, tudo fornece elementos significativos para a leitura e interpretação posterior daQuele depoimento, bem como para a compreensão do universo investigado. Sempre dirigida de acordo com os objetivos por isso sobre a vida do entrevistado só interessa aquilo que vai ser inserido na pesquisa ${ }^{(5)}$.

O local onde as entrevistas serão realizadas não pode existir situações externas como telefonema, amigo, filho, entre outros, fazendo Que o entrevistado perca o "fio da meada", se distraia, se disperse do contexto e se veja obrigado a retornar a narrativa de outro ponto ou até mesmo desistir. Pessoas conversando próximas, transitando no local estes sinais costumam aguçar a ansiedade com relação ao tempo de duração do depoimento ${ }^{(6)}$.

Realizar entrevistas é algo Que depende fundamentalmente de 
experiência de campo. Parece Que por mais Que se saiba, tem Que estar atento a postura adeQuada à realização das entrevistas semiestruturadas, encontrarem a melhor maneira de formular perguntas sem induzir a resposta, ter algum controle das expressões corporais evitando gestos de aprovação, rejeição, dúvida, entre outros.

O pesquisador deve estar sempre atento aos objetivos, obrigando-o a colocar-se sempre a escuta do Que é dito, e refletir sobre a fala, sua forma e conteúdo, observando tonalidade da voz, clareza, gestos Que acompanham a fala ou substituam essa fala.

Um problema particular da entrevista não diretiva é o silêncio Que por vezes se produzem Quando o entrevistador tem muito Que dizer, mas está pensando como dizer; aQueles Quando o indivíduo Quer dizer algo, mas não sabe como dizê-lo; e aQueles que ele não tem nada a dizer ${ }^{(6)}$.

Nas gravações, deve-se observar sempre se a nossa fala está presente ou constante, pois teremos Que analisar criticamente nosso próprio desempenho e corrigi-lo As formas de colher, transcrever e interpretar relatos orais têm sido objeto de severas críticas por parte da sociologia, no Que diz respeito à chamada garantia de confiabilidade ${ }^{(7)}$

Os relatos gravados e transcritos, assim como os procedimentos utilizados para colhê-los, devem estar acessíveis a diferentes pesQuisadores Que não participam da pesQuisa em Questão, para Que cada um possa fazer sua própria interpretação do conteúdo dos relatos colhidos e dessa forma, auxiliar na validação dos resultados apresentados ${ }^{(6)}$.

As transcrições completas de parte das entrevistas ao corpo do relatório de pesquisa pode ser uma estratégia para Que o leitor tenha acesso ao chamado "material bruto" e possa tirar suas conclusões.

Durante a entrevista, no caso do entrevistador sentir necessidade de explicar a pergunta ou tema ao entrevistado várias vezes, tornase necessário retirá-la do roteiro, pois Quando se tenta explicar demais, acaba-se dizendo, de um modo ou de outro, o Que se espera Que o outro responda.

Com o objetivo de identificar a utilização da entrevista não diretiva em grupo, buscaram-se os estudos dos membros do Grupo de Pesquisa "Saúde da Criança/ Cenário Hospitalar".

O estudo intitulado como "Experiências de situações de morte: depoimentos dos estudantes da Escola de Enfermagem Anna Nery da Universidade Federal do Rio de Janeiro" foi de natureza Qualitativa e utilizou a entrevista não diretiva Que foi subsidiada por três temas: experiências relacionadas com as situações de morte no decorrer do curso de graduação; momentos nos Quais as situações de morte foram apresentadas, discutidas e/ou Questionadas durante o desenvolvimento dos programas curriculares interdepartamentais; conhecimentos teóricos e/ou práticos transmitidos pelos professores ou por outros profissionais, em salas de aula e/ou nos campos de prática. Os sujeitos do estudo eram Quatro grupos de Quatro alunos $^{(12)}$.

O estudo intitulado "A (con)vivência da família com o escolar em controle da doença oncológica: perspectivas para a enfermagem pediátrica" foi uma pesquisa de natureza Qualitativa, tipo estudo de caso, utilizando a entrevista não diretiva em grupo com sete familiares, divididos em dois grupos, Que acompanhavam os escolares no ambulatório de Pediatria do Hospital do Câncer I,do Instituto Nacional de Câncer localizado no Município Rio de Janeiro.
Os temas Que subsidiaram a entrevista não-diretiva foram os seguintes: o entendimento da família Quanto à expressão "em controle da doença oncológica”; estratégias de convivência após a entrada no grupo de controle; e atendimento do escolar no ambulatório de pediatria oncológica ${ }^{(9)}$.

O estudo intitulado "A (con)vivência da família frente à hospitalização da criança com distúrbio hematológico: perspectivas para a enfermagem pediátrica" utilizou a abordagem Qualitativa, tipo estudo de caso. O cenário do estudo foi a enfermaria de pediatria Hospital escola da Universidade do Estado do Rio de Janeiro. Os sujeitos do estudo são sete familiares, divididos em dois grupos, Que acompanhavam crianças com distúrbios hematológicos, internadas na enfermaria de pediatria e Que possuem histórico de hospitalização anteriores. Os procedimentos metodológicos foram: a entrevista não diretiva em grupo, observação participante com diário de campo e consulta aos prontuários com auxílio de um formulário. Após o aceite do familiar/acompanhante foi apresentado seis temas que subsidiaram a entrevista: a escolha do membro da família para acompanhar a criança durante a hospitalização; informações sobre a doença; cuidados no hospital e após alta; relacionamento da família com a criança e relacionamento das equipes de enfermagem e de saúde. Vale destacar que após a validação dos temas para atender os objetivos do estudo ;com o primeiro encontro com o grupo, não foi necessário nenhuma modificação nos temas para o próximo encontro ${ }^{(10)}$.

A minha dissertação intitulada "O conhecimento da família acerca da saúde das crianças de um a cinco anos em uma comunidade ribeirinha: subsídios para a enfermagem pediátrica", tendo como cenário de estudo uma comunidade ribeirinha em Povoação, no Município de Linhares do Estado do Espírito Santo. A escolha dos 17 familiares foi aleatória, com participação voluntária. Os sujeitos foram divididos em cinco grupos, identificados com pseudônimos de tipos de peixe da região, para garantir-lhes o anonimato.Os procedimentos metodológicos foram o formulário e a entrevista não-diretiva em grupo, a fim de obter dados referentes ao universo familiar. Os temas Que subsidiaram a entrevista não-diretiva em grupo, elaborados com base nas cinco ações básicas do Programa de Assistência Infantil à Saúde da Criança (PAISC) e Atenção Integrada às Doenças Prevalentes na Infância (AIDPI), foram os seguintes: pessoa Que cuida da criança na família; vacina da criança; amamentação (idade); alimentação diária; e cuidado com a criança com problemas de saúde (febre, diarréia, tosse, problemas de pele, Queimaduras, fraturas entre outros) ${ }^{(8)}$.

Vale ressaltar Que esse estudo não foi desenvolvido no cenário hospitalar tendo em vista Que a EEAN/UFRJ firmou convênio MINTER com a Faculdades Associadas do Espírito Santo (FAESA),e a líder do grupo de pesquisa/orientadora aceitou orientar o estudo considerando a temática saúde da criança.Esse fato propiciou Que a técnica fosse também validada no espaço extra hospitalar com êxito.

O estudo intitulado "Interação familiar/acompanhante e equipe de enfermagem no cuidado à criança hospitalizada: perspectivas para a enfermagem pediátrica" O cenário do estudo é a unidade de internação pediátrica (UIP) de um hospital de ensino, assistência e pesquisa, especializado em pediatria e localizado no Município do Rio de Janeiro. Os sujeitos foram Quatro enfermeiros, uma técnica e uma auxiliar de enfermagem, Que atuavam na UIP e sete membros 
de famílias diferentes Que acompanhavam as crianças internadas na referida unidade. A escolha dos sujeitos se deu pelo fato das relações do cuidado se dar mais especificamente entre a equipe de enfermagem e o familiar.

Os procedimentos metodológicos foram a entrevista não diretiva em grupo, formulário para caracterização dos sujeitos, observação participante, consulta aos prontuários das crianças e aos documentos: normas e rotinas do hospital e manual do acompanhante. Os temas Que subsidiaram essa entrevista para o grupo de membros de família foram:cuidados feitos pelos familiares e pela equipe de enfermagem; relacionamento da equipe com a criança e com a família;e relacionamento da família com a criança.Para os membros da equipe de enfermagem, os temas foram:cuidado do familiar com a criança;cuidado da eQuipe com a criança;relacionamento da família com a criança e da equipe com o familiar $^{(1)}$.

Vale destacar Que foi realizada a validação dos temas com vistas a atender os objetivos do estudo. Após o encontro com os primeiros grupos de membros de famílias e equipe de enfermagem, verificouse Que os temas foram entendidos pelos sujeitos, não sendo necessária nenhuma modificação nos temas para os próximos encontros. Para realização da entrevista, foram formados grupos distintos, de familiares e de elementos da equipe de enfermagem, sendo dois grupos de membros de famílias com três indivíduos no primeiro grupo e Quatro no segundo grupo; e dois grupos de membros da equipe de enfermagem com três indivíduos em cada grupo. Vale destacar que a escolha dos familiares/ acompanhantes se deu de forma aleatória e voluntária, sendo um acompanhante por enfermaria. Em relação à equipe de enfermagem, a escolha foi, também, aleatória e voluntária, de acordo com a disponibilidade, tendo em vista Que a entrevista ocorreu no horário de serviço. No início do encontro foram apresentados os temas e os sujeitos ficaram livres para falar o Que Quisessem, conforme sua necessidade ${ }^{(11)}$.

A pesquisa intitulada "Os doutores da alegria na unidade de internação pediátrica: experiências da equipe de enfermagem", foi de natureza Qualitativa,utilizando a entrevista não diretiva em grupo..Os sujeitos do estudo foram 10 membros da equipe de enfermagem.O cenário do estudo foi diferentes unidades de um hospital pediátrico do Município do Rio de Janeiro,divididos em um grupo composto de Quatro membros e dois grupos de três membros. Após o aceite dos membros da equipe de enfermagem foi apresentado os temas Que subsidiaram a entrevista não diretiva em grupo foram: conhecimento sobre atuação dos doutores da alegria e experiência profissional com eles ${ }^{(13)}$.

\section{COLETA DE DADOS}

Para melhor entendimento da técnica, descrevo os caminhos percorridos na utilização da entrevista não diretiva em grupo na minha dissertação. Inicio fazendo uma explanação acerca da minha chegada ao Distrito de Povoação Município de Linhares/Espírito Santo. Fui para a creche, onde num local utilizado como berçário, organizei os cartazes com cada tema e afixando-os na parede. Em seguida, distribui as cadeiras em semicírculo para obter um ambiente aconchegante e favorecer a leitura dos cartazes. Numa mesa, coloquei vários tipos de doces para facilitar a descontração dos sujeitos e estabelecer uma relação de empatia. Após deixar organi- zado o ambiente, fui às casas onde residem as famílias Que tinham crianças de um a cinco anos, para convidá-las a participarem da pesquisa, explicando os objetivos da mesma. Marquei a reunião para a sala da creche, mas devido às atividades do projeto de extensão, o encontro foi remarcado para outro dia.

No dia remarcado para a entrevista, o grupo do citado projeto de extensão da Escola Superior de Ciências da Santa Casa de Misericórdia de Vitória (EMESCAM) estava utilizando o espaço da creche. Então, por sugestão e aQuiescência de todos, retiramos os cartazes com os temas e fomos para o Quintal da casa de uma avó. Lá chegando, providenciamos a arrumação dos temas e, depois Que todos se acomodaram, expliquei os objetivos do estudo, os temas que seriam abordados e os itens do Termo de Consentimento Livre e Esclarecido. Após a explicação, os familiares aceitaram participar do estudo, confirmando através da impressão digital, Quando analfabetos, ou da assinatura.

Nesse primeiro grupo, os familiares não entenderam os temas. Dessa forma, resolvi, naQuele momento, fazer uma explicação clara e concisa para iniciar a entrevista. A outra dificuldade foi o nível de instrução de cinco familiares Que eram analfabetos ou o entendimento sobre o tema não foi claro.Com isso, foi necessária uma nova explicação para dar seguimento à entrevista. Vale destacar Que, como os familiares trouxeram as crianças, distribui previamente os doces e iniciei a entrevista depois Que as crianças começaram a brincar.

Quando expliquei Que os depoimentos seriam gravados, ocorreu uma reação inesperada de um familiar, dizendo Que não falaria com a máouina, ou seja, o gravador por "medo"; sendo assim, gravei primeiro a minha voz, reproduzindo-a em seguida para Que os familiares escutassem e, assim, aceitassem a utilização do gravador; somente uma delas concordou, porém ficou sem olhar para a pesquisadora, relatando sobre o tema de forma rápida e descompassada. As outras duas mães não aceitaram gravar os seus relatos. Após a entrevista com o primeiro grupo de familiares, houve necessidade de adaptação Quanto à articulação dos temas com as figuras representativas. Constatou-se Que os temas foram entendidos pelos familiares, não ocorrendo também nenhuma alteração com os outros três grupos subseqüentes entrevistados. Os grupos foram formados por três a cinco pessoas, visando à interação entre elas com vistas à obtenção das informações para atender aos objetivos do estudo.

\section{CONSIDERAÇÕES FINAIS.}

Com base no exposto, concluo que a entrevista não-diretiva em grupo, possibilita o pesquisador articular teoria e prática em torno de uma proposta de estudo, demandando esforço, leitura e experiência e também implica em um olhar para captar sinais, recolher indícios, descrever práticas, atribuir sentido a gestos e palavras, entrelaçando fontes teóricas e materiais empíricos durante o desenvolvimento da entrevista.

Em todos os estudos descritos, as dificuldades aparecem seja no âmbito hospitalar ou na comunidade, mas há possibilidade de adaptações por parte do entrevistador,tornando necessário saber olhar, escutar, e principalmente, Que a subjetividade precisa estar incorporada ao processo do conhecimento, buscando formas adeeuadas para utilizar essa abordagem metodológica. 


\section{REFERÊNCIAS}

1. Tobar F, Yalour MR. Como fazer teses em saúde pública: conselhos e idéias para formular projetos e redigir teses e informes de pesquisas. Rio de Janeiro: Fiocruz; 2001.

2. Eco U. Como se faz uma tese. São Paulo: Perspectiva; 1996.

3. Minayo MCS. O desafio do conhecimento: pesQuisa Qualitativa em saúde. $8^{\text {a }}$ ed. São Paulo: Hucitec; 2004.

4. Chizzotti A. Pesquisa em ciências humanas e sociais. $7^{\mathrm{a}}$ ed. São Paulo: Cortez; 2005.

5. Lakatos EM, Marconi MA. Fundamentos de metodologia científica. São Paulo: Atlas; 1995

6. Richardson RJ. Pesquisa social: métodos e técnicas. $3^{\text {a }}$ ed. São Paulo: Atlas; 1999.

7. Polit DF, Beck CT, Hunger BP. Análise de dados Qualitativos. In: Polit DF, Becck CT, Hunger BP. Fundamentos de pesQuisa em enfermagem: método, avaliação e utilização. $5^{\text {a }}$ ed. Porto Alegre: Artmed; 2004. p. 357-77.

8. Hoffmann MV. O Conhecimento da família acerca da saúde das crianças de um a cinco anos numa comunidade ribeirinha: subsídios para a enfermagem pediátrica [tese]. Rio de Janeiro: Escola de Enfermagem Anna Nery, Universidade Federal do Rio de Janeiro; 2007.
9. Couto LL. A (con)vivência da família com o escolar em controle da doença oncológica: perspectivas para a enfermagem pediátrica [tese]. Rio de Janeiro: Escola de Enfermagem Anna Nery, Universidade Federal do Rio de Janeiro; 2004.

10. Cardoso VNS. A (con)vivência da família frente a hospitalização da criança com distúrbio hematológico: perspectivas para a enfermagem pediátrica [tese]. Rio de Janeiro: Escola de Enfermagem Anna Nery, Universidade Federal do Rio de Janeiro; 2006.

11. Souza TV. Interação familiar/acompanhante e equipe de enfermagem no cuidado à criança hospitalizada: perspectivas para a enfermagem pediátrica [tese]. Rio de Janeiro: Escola de Enfermagem Anna Nery, Universidade Federal do Rio de Janeiro; 2007.

12. Santos NMP. Experiências de situações de morte: depoimentos das estudantes da Escola de Enfermagem Anna Nery/UFRI [tese]. Rio de laneiro: Escola de Enfermagem Anna Nery, Universidade Federal do Rio de Janeiro; 1996.

13. Oliveira RR,Oliveira ICS. Os doutores da alegria na unidade de internação pediátrica: experiências da eQuipe de enfermagem. Esc Anna Nery Rev Enferm 2008; 12 (2): 230-6. 